\title{
REDUCING COMPUTATIONAL TIME IN TURBULENT JET MODELLING FOR GAS DISPERSION SIMULATION
}

\author{
E. S. FERREIRA $\mathrm{Jr}^{1}{ }^{1}$, T. FERREIRA ${ }^{1}$ and S.S.V. VIANNA ${ }^{1}$ \\ ${ }^{1}$ University of Campinas (Unicamp), School of Chemical Engineering \\ E-mail para contato: elmo@feq.unicamp.br and $\underline{\text { savio@ feq.unicamp.br }}$
}

\begin{abstract}
The CFD model combines transport phenomena and numerical mathematics to solve physical problems. Although numerical modelling of flow scenarios is the cutting edge of flow modelling, there seems to be room for improvement. This paper proposes an approach for enhancing computation of turbulent jet as far as processing time is concerned. The methodology is based on an equivalent diameter and velocity profile calculated downstream the jet orifice. The novel model DESQr (Diameter of Equivalent Simulation for Quick Run) shows good agreement with experimental data and a significant computational time reduction is observed. Findings are also compared with commercial (ANSYS CFX) CFD tool.
\end{abstract}

\section{INTRODUCTION}

Computational Fluid Dynamics (CFD) has more recently been applied in various industrial scenarios. The chemical industry, in particular, has major interest in flow modelling as it is of crucial important in all stages of design.

Simulation time is an important point to be considered in any CFD case. More recently the utilisation of LES (Large Eddy Simulation) and RANS (Reynolds Averaged Navier Stokes) approach has played an important role in engineering. The benefits of the former outweigh the computational time when RANS cannot provide reliable results, particularly when significant gradient are present. Having said that, LES is computationally expensive for the industry standards where quick responses are demanded.

The current research is focused on the modification of the low momentum LES code (namely FDS-Fire Dynamic Simulator) in order to deal with jet scenarios in an accurate manner and faster than traditional approaches. A novel jet model DESQr (Diamenter of Equivalent Simulation for Quicker Run) is proposed.

Findings are compared with experimental data and ANSYS CFX and good agreement is observed with significant computational time reduction. 


\section{METHODOLOGY}

The framework of FDS based on Large Eddy Simulator (LES) developed by National Institute of Standards and Technology (NIST) for prediction of fire behaviour was considered. The code solves numerically mass, momentum, energy and mixture fraction equations alongside Smagorinsky sub-grid models (Mcgrattan et al, $2010 \mathrm{a}, \mathrm{b}$ ).

\subsection{DESQr - Diameter of Equivalent Simulation for Quick Run}

The idea behind the method is fairly simple. It relies on the new boundary conditions based on isentropic jet release to be modelled downstream the jet orifice.

The updated model diameter $\left(D_{M}\right)$ is presented in equation 1. It is a function of the distance from the jet leak $(z)$, mass flow rate and the centreline velocity. It has been adapted from Benintendi (2010).

$$
D_{M}=2 \cdot \sqrt{2} \cdot 0.082 \cdot z \sqrt{-\ln \left(1-\frac{m_{e} \cdot C_{e}}{2 \Pi \cdot \rho_{a} \cdot v(0, z) \cdot D_{\mathrm{eq}} \cdot z \cdot 0.082^{2}}\right)}
$$

In the equation above $m_{e}$ is the mass flow rate at jet exit, $\rho_{a}$ is the specific mass of the air in a normal conditions of temperature and pressure and $C_{e}$ is the entrainment coefficient. Tate (2012) reports a large value for the entrainment coefficient for axisymmetric jets. For axisymmetric jets in a non-stratified and stagnated ambient fluid the entrainment coefficient is $0.08 \pm 0.029$ (Matulkca, 2014). The value of 0.05 was used in the current work.

The jet centreline velocity in $z$ direction $(v(0, z))$ (Benintende, 2010) and the equivalent diameter $\left(D_{\text {eq }}\right)$ developed by Schefer et al (2007) and Birch et al (1987) are given by:

$$
\begin{aligned}
& V(0, z)=6 \cdot \frac{D_{\mathrm{eq}} \cdot V_{e}}{z} \\
& D_{\mathrm{eq}}=\mathrm{D}_{e} \cdot \sqrt{\frac{P_{e}}{P_{a}}}
\end{aligned}
$$

A detailed description of the model can be found elsewhere (Ferreira Jr. \& Vianna, 2014; Benintende, 2010).

In order to verify the model previously discussed, an investigation of turbulent jet velocity behaviour was performed. The computation domain is shown in Figure 1. Furthermore, the diameter estimation using DESQr model is applied, reducing considerably the elapsed time simulation of the turbulent jet. 


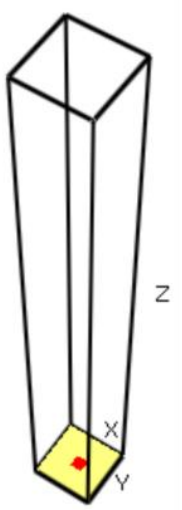

Figure 1 - Computational domain for velocity profile investigation.

The simulation of air jet leaked from a nozzle $\left(D_{e}\right)$ of $2.7 \mathrm{~mm}$ and $340 \mathrm{~m} / \mathrm{s}$ exit velocity $\left(V_{e}\right)$ was performed in a rectangular box of $20 \mathrm{~mm}$ length, $20 \mathrm{~mm}$ width and $500 \mathrm{~mm}$ height. Velocity monitor points were distributed in the centre of the computational domain in accordance with the experiment conducted by Birch et al. (1987).

Figure 2 (a) shows a sketch of the jet pattern observed by Birch et al (1987). Figure 2 (b) illustrates the modelled region proposed in this work. Two distances downstream the jet leak were considered $(95 \mathrm{~mm}$ and $190 \mathrm{~mm}$ ). As a result two regions were modelled as shown in Figure 2 (b). Thus, new boundary conditions namely, the jet nozzle becomes $D_{M}$ and the exit velocity, are considered in the numerical simulation.

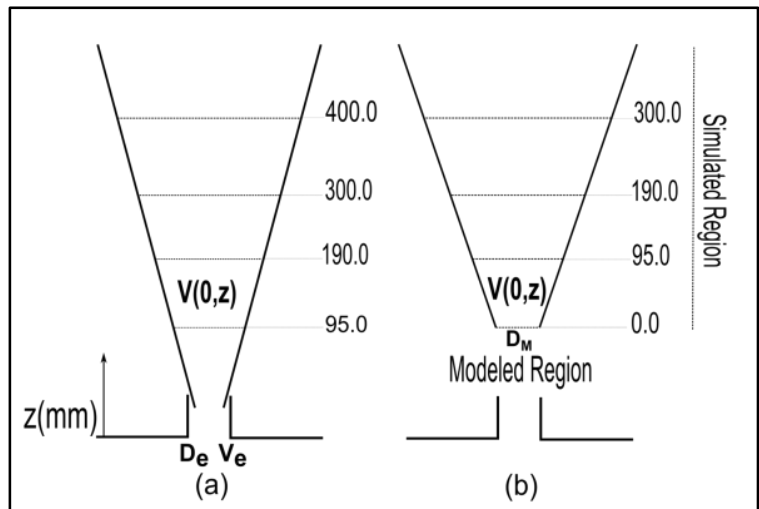

Figure 2 - (a) Experimental jet and its respective centreline velocity monitoring regions. (b) Jet modelling for various monitoring downstream distances.

As the potential core extends up to $z / D_{e}=0.6$ for sonic jets (Chuech, 1989) monitoring points were adjusted accordingly to consider the very first recording velocity immediately after the release.

The simulations comprising 0.025 million of cells were performed on a computer with $3.40 \mathrm{GHz}$, core $\mathrm{i} 7$ and $8 \mathrm{~GB}$ of RAM. 


\section{RESULTS}

Figure 3 (a) shows the jet centreline velocity decay for experimental data, FDS (original model) and ANSYS CFX code. It is clearly shown in Figure 3 (a) that the simulations satisfactorily reproduce the experimental data, having a significant initial drop and a smooth decay at the end. Figure 3 (b) shows the elapsed FDS simulation time. The simulation took approximately 51 hours to complete when using FDS original model.

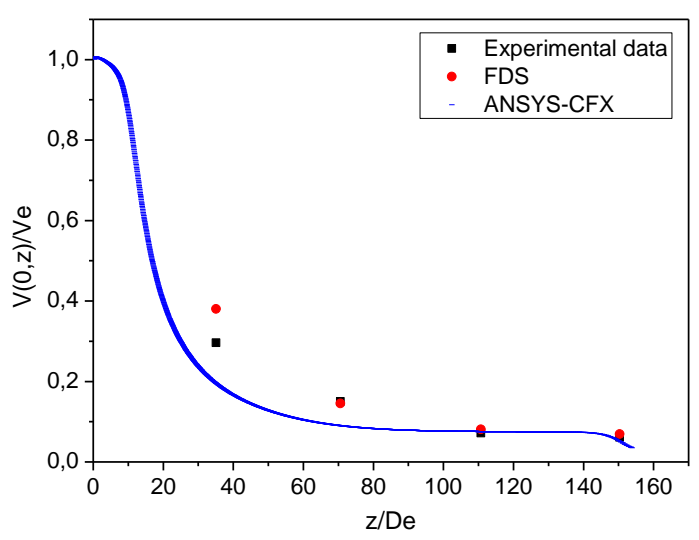

(a)

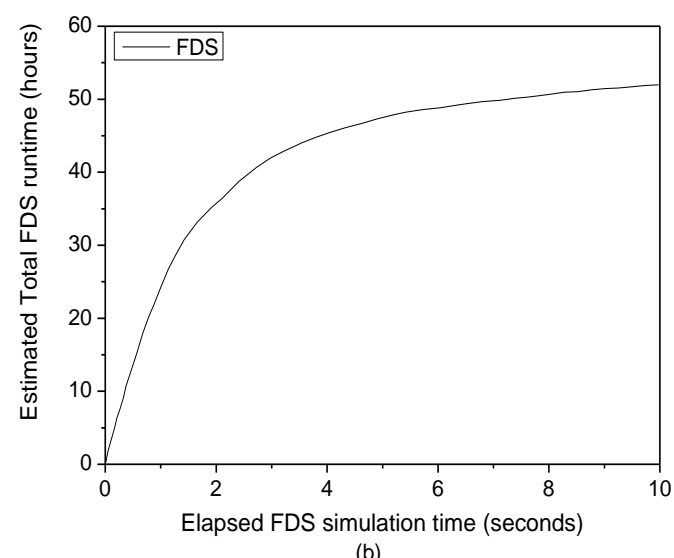

(b)

Figure 3 - (a) Jet centreline velocity profile. Comparison among experimental data, FDS code and ANSYS CFX code. (b) Elapsed FDS simulation time without using DESQr model.

Figure 4 presents the findings when DESQr model is considered. Analysis of Figure 4 (a) shows the jet centreline velocity profile for two different codes. It can be seen that DESQr results agree well with experimental data. Analysis of Figure 4 (b) shows a significant computational time reduction of 36 hours for the same case when compared with Figure 3(b).
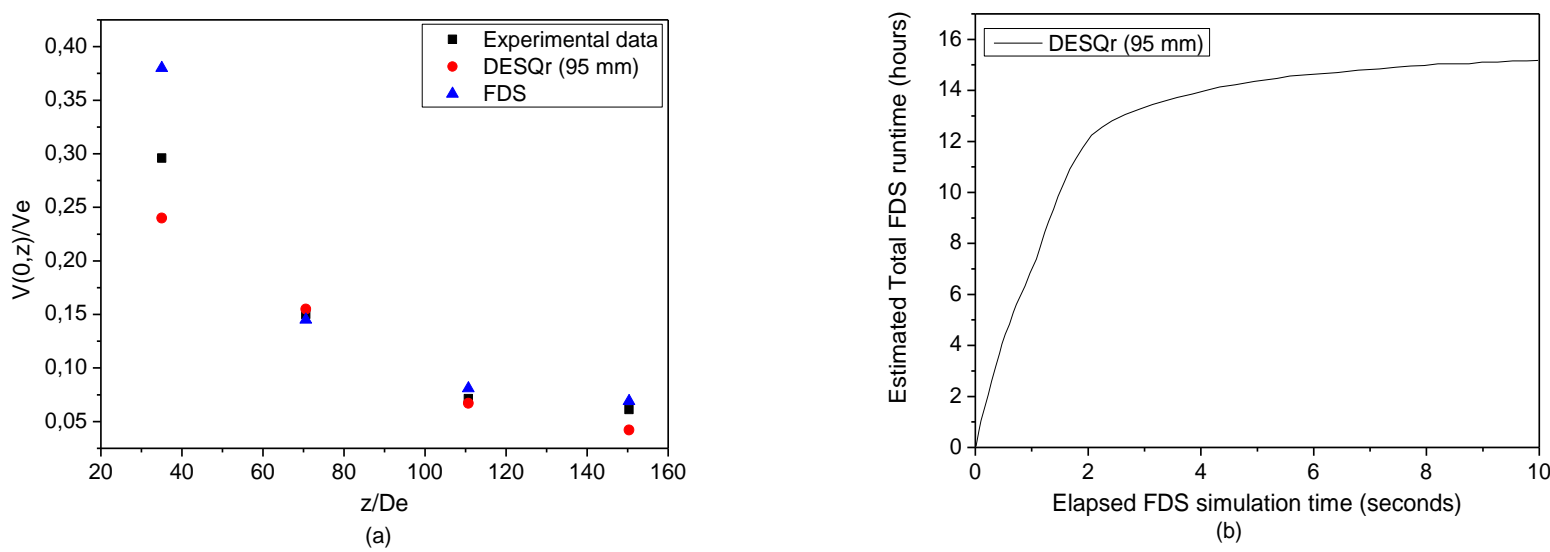

Figure 4 - (a) Jet centreline velocity profile. Comparison between experimental data, jet modelling at $95 \mathrm{~mm}$ height and FDS code. (b) Elapsed FDS simulation time using jet modelling at $95 \mathrm{~mm}$ height. 
Analysis of Figure 5 (a) also shows good agreement with experimental data when considering the distance of $190 \mathrm{~mm}$ from the jet leak. Further improvement in an elapsed simulation time is achieved, as shown in Figure 5 (b).
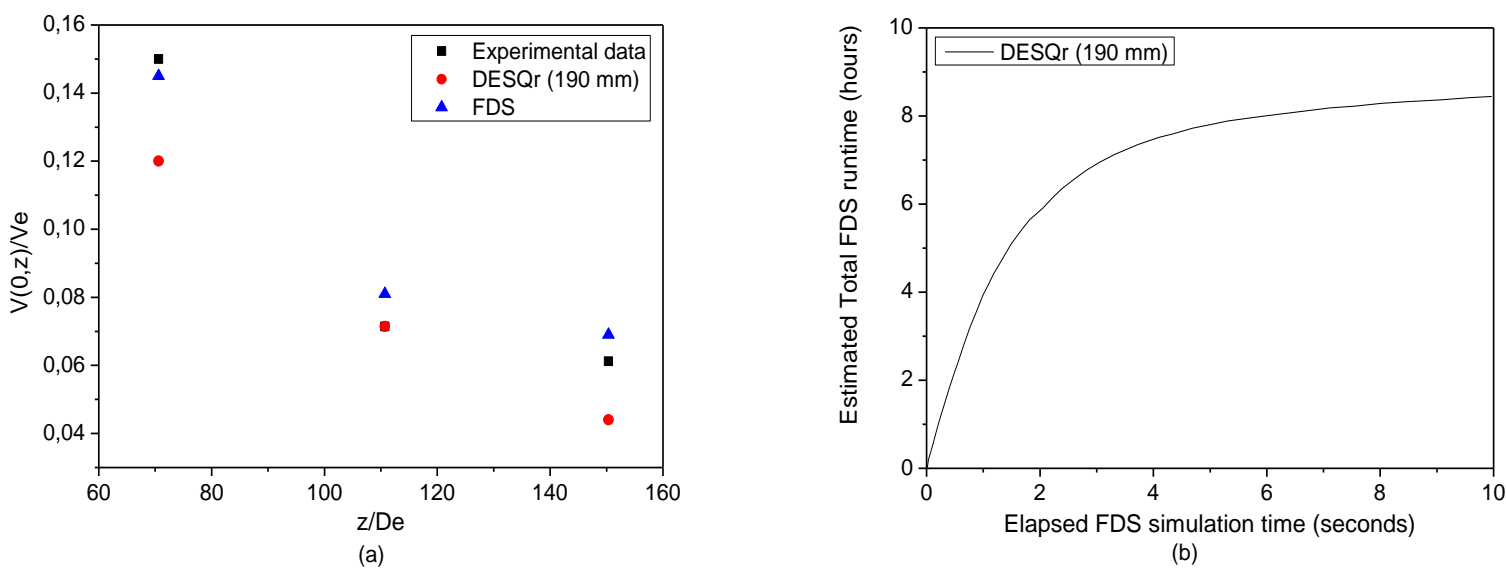

Figure 5 - (a) Jet centreline velocity profile. Comparison between experimental data, jet modelling at $190 \mathrm{~mm}$ height and FDS code. (b) Elapsed FDS simulation time using jet modelling at $190 \mathrm{~mm}$ height.

Figure 6 shows the simulation time comparison using DESQr and FDS model. The time reduction is notable.

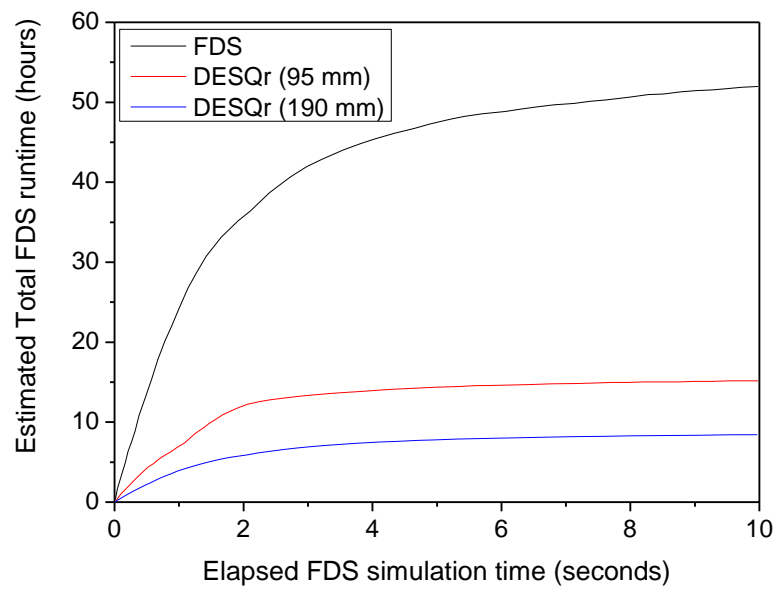

Figure 6 - Simulation time comparison using DESQr for $95 \mathrm{~mm}, 190 \mathrm{~mm}$ height and the original FDS model.

\section{CONCLUSIONS}

A novel jet model for numerical simulation of turbulent jet has been proposed. The model has been implemented in FDS (Fire Dynamic Simulator) framework. Comparison with experimental data 
ensured good agreement. The findings have also been compared with commercial ANSYS CFX and good agreement was also observed.

The model also reduced the computational time significantly. There seems to be a very good indication that a promising approach has emerged. Further assessment is necessary to verify the application of the model when calculating flammable gas cloud volumes as well as toxic cloud volumes.

\section{REFERENCES}

BENINTENDI, R.; Turbulent jet modeling for hazardous area classification, J. of Loss Prev. in the Proc. Ind., v. 23, p. 373-378, 2010.

BIRCH, A. D.; HUGHES, D. J.; and SWAFFIELD, F. Velocity Decay of High Pressure Jets. Combust. Sci. and Technol., v. 52, p. 161-171, 1987.

CHUECH, S. G.; LAI, M. C.; FAETH, G.M.F. Structure of Turbulent Sonic Underexpanded Free Jets, Aiaa J., v. 27, No. 5, May 1989, pp. 549-559.

FERREIRA Jr, E. S.; VIANNA, S. S. V. A Novel Free and Advanced Large Eddy Simulation Computational Fluid Dynamics Tool for Gas Dispersion, Int. J. of Model. and Simul. for the Pet. Ind., Submitted, 2014.

MATULKA, A.; LÓPEZ, P.; REDONDO, J. M.; TARQUIS A. On the entrainment coefficient in a forced plume: quantitative effects of source parameters, J. Eur. Geoscience Union., v. 21, p. 269-278, 2014.

MCGRATTAN, K.; HOSTIKKA S., FLOYD J., BAUM H., REHM R., MCDERMOTT, W. M. R. Fire dynamics simulator (version 5) Technical Reference Guide, April 2010.

MCGRATTAN, K.; MCDERMOTT, R.; HOSTIKKA, S.; FLOYD, J. Fire dynamics simulator (version 5) User guide, NIST Special Publication 1019-5, April 2010.

SCHEFER R. W.; HOUF H.G.; WILLIAMS T.C.; BOURNE B.; COLTON J. Characterization of high-pressure, under-expanded hydrogen-jet flames. Int. J. of Hydrogen Energy, v. 32(13), p. 2081-2093, 2007.

TATE, P. M. The rise and dilution of buoyant jets and their behaviour in an internal wave field, Ph.D. thesis, University of New South Wales, Sydney, Australia, 2002. 
19 a 22 de outubro de 2014

Florianópolis/SC

\section{Engenharia Química}

